\title{
Chapter 18 \\ Shaping the Future of Global Health: \\ A Review of Canadian Space Technology Applications in Healthcare
}

\author{
Aranka Anema, Nicholas D. Preston, Melanie Platz and Chandana Unnithan
}

\begin{abstract}
Technology innovation is exponential globally and the global health sector is imbibing these rapidly. In Canada, the growth in space technology innovations have been driven by the UN 2030 sustainable development goals (SDGs) and applied to public health and foreign aid priorities and policies. In this chapter, we explore the shared vision of space and global health in Canada, through an appraisal of contributions.
\end{abstract}

\subsection{Introduction: Era of Exponential Technologies}

We are experiencing a global revolution in technology innovation that is growing at an exponential rate. Leading futurist Ray Kurzweil has suggested that while human development was historically characterized by local and linear shifts in knowledge and technology, the past 100 years have been defined by technological innovations that are both global and exponential. ${ }^{1}$ Proponents of 'exponential technologies' suggest that these trends lead to rapid and exponential increases in innovation. This jump from linear to exponential technologies over recent years is illustrated by the comparison of the NASA Apollo Guidance Computer to today's iPhone. The Apollo guidance computer was revolutionary at its time in terms of computing power; it

\footnotetext{
${ }^{1}$ Kurzweil R. 2005. The Singularity Is Near: When Humans Transcend Biology. Penguin Publishing, USA.

${ }^{2} \mathrm{O}$ 'Brien F. The Apollo Guidance Computer, Architecture and Operation”. Springer, 2010.
}

\author{
A. Anema (ه) \\ Global Health PX, Vancouver, Canada \\ e-mail: aranka.anema@gmail.com \\ N. D. Preston \\ University of Victoria, Victoria, Canada \\ M. Platz \\ Pedagogical University of Tyrol, Innsbruck, Austria \\ C. Unnithan \\ Torrens University Australia, Melbourne, Australia


cost millions to build and was the size of a car. ${ }^{2}$ In 2018, the iPhone is 120 times computationally faster, costs a couple hundred to manufacture and fits into a back pocket.

Technology entrepreneurs have postulated a theoretical framework to further understand the concept of exponential technologies, known as the 'Six Ds'. ${ }^{3}$ Once a technology has been 'digitized', or information-enabled, it has the potential to scale exponentially by virtue of being easily accessed, shared and distributed. The development cycle of exponential technologies can be 'deceptive' during its initial periods of growth, and its fullest potential difficult to predict owing to unprecedented leaps in innovation. Exponential technologies are often 'disruptive' by virtue of their ability to outperform traditional solutions in effectiveness and cost, opening new market opportunities. Technologies are being 'demonetized', as software and hardware development becomes cheaper to manufacture, to the point of being free of cost. Finally, exponential technologies are 'dematerialized', with digitization of functionality removing the need for physical products; and they are increasingly being 'democratized', by way of becoming widely available to potential users. Examples of exponential technologies include: 3D printing, artificial intelligence (AI), industrial robots, robotics, digital medicine, drones, internet connectivity, genetic sequencing, cell phones, synthetic biology and nanotechnology.

Over the recent years, we have witnessed a proliferation of exponential technologies in medicine and healthcare that are poised to transform health globally. Some salient examples include wearable technologies, which have seen annual revenue market growth from $\$ 0.75$ billion in 2012 to $\$ 5.8$ billion in $2018^{4}$; human genome sequencing, which has dropped from $\$ 1$ billion in 2001 to $\$ 500$ in $2017^{5}$; This trend is largely fuelled by private sector start-ups, with latest market insights estimating there are now over 100 new entrepreneurial ventures transforming healthcare with AI. ${ }^{6}$ Looking to the $2020 \mathrm{~s}$, the Internet of Things (IoT) will generate exponential amounts of data from devices and sensors. 5G networks will be 10-100 times faster than current mobile broadband networks, enabling transfer of vast amounts of highfidelity, real-time data. And, once powered by the analytic abilities of AI and machine

\footnotetext{
${ }^{3}$ Ramirez VA. The 6 Ds of Tech Disruption: A Guide to the Digital Economy. November 222016. Singularity Hub. Available at: https://singularityhub.com/2016/11/22/the-6-ds-of-tech-disruptiona-guide-to-the-digital-economy/.

${ }^{4}$ Wearable Technology-The Next Mobility Market is Booming-Wearable Techgoo.gl/Mx27nG.

${ }^{5}$ Shendure, Jay, Shankar Balasubramanian, George M. Church, Walter Gilbert, Jane Rogers, Jeffery A. Schloss, and Robert H. Waterston. "DNA sequencing at 40: past, present and future." Nature 550, no. 7676 (2017): 345.

${ }^{6} \mathrm{CB}$ Insights. From Virtual Nurses To Drug Discovery: 106 Artificial Intelligence Startups In Healthcare Feb 03, 2017. Available at: https://www.cbinsights.com/research/artificial-intelligencestartups-healthcare/.
} 
learning, data will inevitably become a new form of capital with blockchain technology as the mechanism for securely storing, distributing, managing and deploying that capital. ${ }^{7}$

\subsection{Leadership in Space Technology for Global Health}

Canada has played a leading role internationally in the translation of space science to terrestrial applications in health. In 2001, the United Nations Committee on the Peaceful Uses of Outer Space (UN-COPUOS) established the Action Team 6 (AT6) as a mechanism for implementing recommendations of the third United Nations Space Conference UNISPACE III (1999). Co-chaired by Canada, an Action Team 6 FollowUp Initiative (AT6FUI) was established with the World Health Organization (WHO) in 2007 to refine domestic and international priorities for public health applications of space technologies. In 2011, AT6FUI held a meeting on 'Space technology for Public Health Actions in the Context of Climate Adaptation" together with UNOOSA and ESA, to foster knowledge exchange, partnerships and discussion around satellite technology applications to climate change and public health. ${ }^{8}$ In 2015 , The United Nations inaugurated an expert group on space and global health under the leadership of the Canadian government, the WHO and the Canadian Space Agency (CSA). This initiative is part of a broader goal to apply space technology to socioeconomic development, articulated in the United Nations Committee on the Peaceful Uses of Outer Space 2015 (UN-COPUOS) Thematic Priority \#5: Strengthened space cooperation for global health. It outlines priority objectives around the use of space technologies and information systems to promote cooperation in emergencies, epidemics and natural disasters. ${ }^{9,10}$ Most recently, in 2017, the CSA and National Research Council of Canada's Industrial Research Assistance Program (IRAP) co-hosted the Space, Health and Innovation conference which aimed to highlight latest research and

\footnotetext{
${ }^{7}$ Lyons P and Hartani R. The Internet Is Fast Approaching 50. How Might It Look At 60? January 23, 2018. Forbes Magazine. Available at: https://www.forbes.com/sites/worldeconomicforum/2018/01/ 23/the-internet-is-fast-approaching-50-how-might-it-look-at-60/\#6e01768a2f99.

${ }^{8}$ Committee on the Peaceful Uses of Outer Space Scientific and Technical Subcommittee Fortyeighth session, Vienna, 7-18 February 2011. Item 5 of the provisional agenda. Implementation of the recommendations of the Third United Nations Conference on the Exploration and Peaceful Uses of Outer Space (UNISPACE III). Available at: http://www.unoosa.org/pdf/limited/c1/AC105_C1_ L305E.pdf.

${ }^{9}$ Committee on the Peaceful Uses of Outer Space Scientific and Technical Subcommittee Fiftyfirst session. Vienna, 10-21 February 2014. Item 6 of the provisional agenda. Space technology for socioeconomic development in the context of the United Nations Conference on Sustainable Development and the post-2015 development agenda. Available at: http://www.unoosa.org/pdf/ limited/c1/AC105_C1_2014_CRP24E.pdf.

${ }^{10}$ DiPippo S. United Nations Office for Outer Space Affairs (UNOOSA). UNISPACE +50 . UN/WHO/Switzerland Conference: Strengthening Space Cooperation for Global Health. UNSPACE Open Session. 24 August 2017. Available at: http://www.unoosa.org/documents/pdf/ unspace/iam/2017/ois-01E.pdf.
} 
development (R\&D) and applications of space technologies into healthcare across Canada. ${ }^{11}$

In this Chapter, we propose a shared vision for Canadian space science contributions to global health and highlight future directions for Canada's contribution to global health technologies towards achieving the United Nations 2030 Sustainable Development Goals (UN SDGs). We review the Canadian Space Agency's (CSA) space technology innovations as applied to domestic healthcare and public health and Canada's foreign aid priorities.

\subsection{Space Technology Applied to Health in Canada}

CSA's mission is to advance the knowledge of space through science and use its discoveries for the good of Canadians and all of humanity. One of its priorities is to use space science and technology for the development of innovative applications on Earth. CSA is actively positioning the private sector to lead domestic space industry innovations and to bring cutting-edge technologies and skills to international markets. Several of CSA's space technologies have been adapted for use in terrestrial healthcare and public health, paving inroads into 'exponential medicine'. Notable examples include spin-off robotics technologies, communication and observation satellites, global positioning systems and remote sensing devices.

\subsubsection{Robotics}

Canadarm2 was designed by MacDonald, Dettwiler and Associates Ltd (MDA) for the CSA to manoever payloads onto the International Space Station (ISS), and is a prime example of how Canadian space technology has been adapted for use in terrestrial healthcare. ${ }^{12}$ Launched into space in 2001, Canadarm 2 has catalyzed several spinoff technologies now applied in specialized surgery and diagnostics across Canada. One example of a spinoff technology is NeuroArm, the world's first robot capable of performing surgery inside magnetic resonance imaging (MRI) machines. NeuroArm uses miniaturized tools such as laser scalpels with pinpoint accuracy and is capable of performing soft tissue manipulation, needle insertion, suturing and cauterization. ${ }^{13}$ Another adaptation of Canadarm 2 for healthcare is the Image-Guided

\footnotetext{
${ }^{11}$ Canadian Space Agency (CSA). Space, Health and Innovation: Emerging challenges, new opportunities and benefits to society. November 29-30, 2017, John H. Chapman Space Centre, Saint-Hubert, Quebec.

${ }^{12}$ Canadian Space Agency (CSA). Canadarm2 Spinoff Technology Transforming Surgery on Earth. Available at: http://www.asc-csa.gc.ca/eng/iss/canadarm2/canadarm2-spinoff-technologytransforming-surgery-on-earth.asp.

${ }^{13}$ Canadian Space Agency (CSA). 2015. Robotic arms lend a healing touch: neuroArm and its legacy. Available at: http://www.asc-csa.gc.ca/eng/canadarm/neuroarm.asp.
} 
Autonomous Robot (IGAR), a digital surgical tool aimed at improving access and precision of minimally invasive surgeries for breast cancer. Working with an MRI scanner, IGAR allows radiologists to identify surgical access points and precision pathways for automated robotic biopsies and ablation. The diagnostic tool has shown to be highly cost-effective and is enabling a new era of minimally invasive excision and treatment of small tumours. ${ }^{14}$ Canadarm 2 has inspired the development of KidsArm, a next-gen surgical tool built at SickKids Hospital's Centre for Image-Guided Innovation \& Therapeutic Intervention (CIGITI). KidsArm is the first image-guided robotic surgical arm in the world specifically designed for pediatric surgery, and aims to assist doctors in fetal, cardiac, neurological and urological surgeries. ${ }^{15}$ Most recently, Canadarm 2 technology is now being adapted for use in digital microscopy to improve hospital diagnoses and clinical workflow.

\subsubsection{Satellites}

Canada currently has five commercial satellites in operation (Anik F1, Anik E1, Anik E2, Nimik and MSAT). Most recently, CSA successfully launched The Canadian Maritime Monitoring and Messaging Microsatellite (M3MSat) in 2016. ${ }^{16}$ CSA is incubating CubeSat technologies in partnership with universities across Canada ${ }^{17}$ and together with the University of Alberta successfully deployed Ex-Alta 1 CubeSat into space which offers potential to catalyze faster, smaller, smarter and cheaper commercial technologies for terrestrial applications. CSA's satellites are being used for both communication and observation purposes, contributing to a global knowledge economy and enabling advanced support in search and rescue teams; ships and aircraft geopositioning information; and cross-geographic communication purposes.

In public health, satellite communications have enabled to e-health, telehealth and telemedicine by enabling digital or telephone communication in rural and remote areas. These capabilities have increased access to healthcare education and delivery in settings with limited telephone infrastructure, allowing for novel applications domestically in Canada's northern geographies as well as internationally. CSA satellites have been used for Earth observation and used to track environmental determinants of health, climatic and weather variables essential to understanding trends in vector-borne and water-borne infectious diseases; zoonotic disease and humanwildlife interaction; agricultural productivity and food security; land-use land-cover

\footnotetext{
${ }^{14}$ Canadian Space Agency (CSA). 2015. Robots from space lead to one-stop breast cancer diagnosis and treatment. Available at: http://www.asc-csa.gc.ca/eng/canadarm/igar.asp.

${ }^{15}$ Canadian Space Agency (CSA). 2015. Canadian Space Technology to Help Sick Children. Available at: http://www.asc-csa.gc.ca/eng/canadarm/kidsarm.asp.

${ }^{16}$ Canadian Space Agency (CSA). 2016. Maritime Monitoring and Messaging Microsatellite (M3MSat). Available at: http://www.asc-csa.gc.ca/eng/satellites/m3msat/default.asp.

${ }^{17}$ CubeSats. Last modified 2017-12-12. Available at: http://www.asc-csa.gc.ca/eng/satellites/ cubesat/default.asp.
} 
change and ecosystem health services; and poverty, urbanism and the social determinants of health. ${ }^{18}$ Global Positioning System (GPS) technology has now become ubiquitous in hand-held mobile phone technology, allowing public health officials and scientists to further pinpoint the precise location of reported risks and gather insights into human behaviour and movement. When combined with population, transportation and infrastructure data, satellite observations can provide real-time tracking, visualization and spatial analysis of public health risks. The Public Health Agency of Canada (PHAC) has used satellite technology to assess domestic water contamination risks in recreational lakes, to evaluate the risk of vector-borne diseases, such as Lyme disease and West Nile virus, and to monitor the spread of pandemic disease outbreaks. ${ }^{19}$

\subsubsection{Remote Sensing}

MacDonald, Dettwiler and Associates Ltd. (MDA) and CSA collaborated to develop RADARSAT- 2 one of world's most advanced commercially available Earth remote sensing technologies. Generating data over expansive territories of land over time, RADARSAT-2's remote sensing produces a high-quality data product that has many applications in marine surveillance, disaster management and defense. RADARSAT2 has strengthened capabilities for mapping, allowing for the creation of Digital Elevation Models (DEM)s, the detection and mapping of centimetre-scale movements at the Earth's surface (InSAR), and the extraction and identification of features to support environment management and security. The RADARSAT Constellation is CSA's latest evolution of the RADARSAT Program, and aims to ensure data continuity, improve operational use of Synthetic Aperture Radar (SAR) and improve system reliability. The three-satellite configuration is planned for launch in 2018, and will provide daily revisits of Canada's land and marine territory, as well as $90 \%$ of the world's surface. ${ }^{20}$

Canada has used RADARSAT-2 technologies to monitor changes in vegetation, humidity in soil, crop productivity and disease transmission patterns. Currently, Canadian researchers are using RADARSAT to improve detection and prevention of urban health risks posed by high heat, air pollution and emergence of vector-borne diseases. ${ }^{21}$ RADARSAT-2 images are used to characterize the pattern of urban landscapes to predict areas susceptible to higher heat and health-related risks. It is being

\footnotetext{
${ }^{18}$ Olson SH, Benedum CM, Mekaru SR, Preston ND, Mazet JAK, Joly DO, and JS Brownstein. 2015. Drivers of Emerging Infectious Disease Events as a Framework for Digital Detection. Emerging Infectious Diseases. 21 (8), 1285.

${ }^{19}$ Space technologies for Health. Bull World Health Organ 2015; 93:519-520.

${ }^{20}$ Canadian Space Agency (CSA). RADARSAT Constellation. Available at: http://www.asc-csa.gc. ca/eng/satellites/radarsat/default.asp.

${ }^{21}$ Canadian Space Agency (CSA). Using satellites to identify potential health risks in cities. Updated: 2017-05-19. Available at: http://www.asc-csa.gc.ca/eng/blog/2017/05/19/using-satellitesto-identify-potential-health-risks-in-cities.asp.
} 
used to identify areas where air is stagnating, posing potentials risks for cardiovascular and respiratory diseases, and to locate sites prone to mosquito breeding and transmission of vector-borne diseases. Satellite imagery has also proven useful for observing changes in ice cover and its impact on food security and health in the north, resulting from both transportation of supplies, drowning risk, and access to hunting grounds.

\subsection{Synergies with Foreign Aid}

Global Affairs Canada manages Canada's diplomatic and consular relations, promotes the country's international trade and leads Canada's international development and humanitarian assistance. One of the hallmarks of Canada's foreign aid approach is the promotion of knowledge transfer and capacity building. CSA-incubated science and technology has been applied in both domestic and international contexts to sustainably improve the lives of vulnerable groups, especially for children, women, Indigenous populations and the elderly. We reviewed space technology applications relevant to Canada's foreign aid priorities and highlight how these may strengthen Canada's global health role in areas of pandemic preparedness, food and nutrition security, disease prevention, disaster relief and human security. CSA innovations in space science and technology have significantly contributed to Canada's foreign aid capabilities and have the potential to shape Canada's future contributions to global health.

The following case studies highlight pandemic preparedness, food and nutrition security, disease prevention and disaster relief.

\subsubsection{Pandemic Preparedness}

Global Affairs Canada has an overt focus on pandemic preparedness for influenza, including minimizing serious illness and overall deaths by reducing the spread of infection through promotion of individual and community actions; protecting the population through strategic provisioning and positioning of pandemic vaccines and implementation of other public health measures; and providing treatment and support for large numbers of persons while maintaining other essential health care. A key aspect of this is ensuring evidence-informed decision making by supporting partnering countries in the rigorous collection, analysis and dissemination of surveillance and scientific information for use by health professionals and public health officials. Collectively these activities contribute to Canada's efforts towards achieving UN SDG 3: ensuring healthy lives and promote well-being at all ages; and SDG11: make cities and human settlements inclusive, safe, resilient and sustainable. 
Canada has been at the forefront of global pandemic preparedness under the WHO International Health Regulations (IHRs). The IHRs (2005) govern international surveillance and response to public health emergencies of international con$\operatorname{cern}^{22}$ and require States Parties abilities to monitor, detect, assess and report public health hazards in a way that does not adversely impact cross-border travel and trade. ${ }^{23}$ A comprehensive evaluation of the functioning of the WHO's IHR(2005) detection process emphasized the need for increased capacity building of States Parties in surveillance, ${ }^{24}$ and notably in low-income countries and fragile states. ${ }^{25}$ Canada pioneered digital biosurveillance for enhancing early detection and response to public health emergencies through the inception of the Global Public Health Intelligence Network in the late 1990s. ${ }^{26}$ Many public health events notifiable under the IHR(2005), such as SARS, H1N1, MERS-CoV and Ebola, have been identified through informal sources. ${ }^{27,28,29}$ Web-based queries and participatory systems also produce cost-effective data for syndromic surveillance. ${ }^{30,31}$

New data products derived from CSA Earth observation satellites enable further risk characterization based on population, climatic and environmental determinants

\footnotetext{
${ }^{22}$ World Health Organization (WHO). Fifty-eighth World Health Assembly Resolution WHA58.3: Revision of the International Health Regulations. Available at: http://www.who.int/ipcs/ publications/wha/ihr_resolution.pdf.2005.

${ }^{23}$ World Health Organization (WHO). WHO's Interim Guidance for the Use of Annex 2 of the IHR (2005): Decision instrument for the assessment and notification of events that may constitute a public health emergency of international concern. Available at: http://www.who.int/ihr/Annex 2_Guidance_en.pdf.2008.

${ }^{24}$ Anema A, Druyts E, Hollmeyer HG, Hardiman MC, Wilson K. Evaluation of the Functioning of the International Health Regulations (2005) Annex 2. Global Health. 2012; 8(1).

${ }^{25}$ Sturtevant JL, Anema A, Brownstein JS. The new International Health Regulations: considerations for global public health surveillance. Disaster Med Public Health Prep. 2007 Nov; 1(2):117-21.

${ }^{26}$ Dion M, AbdelMalik P and Mawudeku A. Big Data and the Global Public Health Intelligence Network (GPHIN). Canada Communicable Disease Report (CCDR). Volume 41-9, September 3, 2015. Available at: https://www.canada.ca/en/public-health/services/reports-publications/canadacommunicable-disease-report-ccdr/monthly-issue/2015-41/ccdr-volume-41-9-september-3-2015data/ccdr-volume-41-9-september-3-2015-data-1.html.

${ }^{27}$ Olowokure B, Pooransingh S, Tempowski J, Palmer S, Meredith T. Global surveillance for chemical incidents of international public health concern. Bull World Health Organ. 2005; 83(12): 928-34.

${ }^{28}$ Barboza P, Vaillant L, Mawudeku A, Nelson NP, Hartley DM, Madoff LC, Linge JP, Collier N, Brownstein JS, Yangarber R, Astagneau P. Early Alerting Reporting Project of the Global Health Security Initiative. Evaluation of Epidemic Intelligence Systems Integrated in the Early Alerting and Reporting Project for the Detection of A/H5N1 Influenza Events. PLoS One. 2013; 8: 1-9.

${ }^{29}$ Anema A, Kluberg S, Wilson K, Hogg RS, Khan K, Hay SI, Tatem AJ, Brownstein JS. Digital surveillance for enhanced detection and response to outbreaks. Lancet Infect Dis. 2014 Nov; 14(11):1035-7.

${ }^{30}$ Hulth A, Gustaf R, Annika L. Web queries as a source for syndromic surveillance. PloS One. 2009; 4(2): e4378.

${ }^{31}$ Freifeld CC CR, Mekaru SR, Chan EH, Kass-Hout T, Lacucci AA, Brownstein JS. Participatory Epidemiology: Use of Mobile Phones for Community-Based Health Reporting. PloS Med. 2010; 7(12): e1000376.
} 
of health, and predictive models for pandemic preparedness planning. ${ }^{32}$ The field of tele-epidemiology refers to epidemiology and space technologies applied to human and animal health and is driving new understandings of environmental determinants of infectious disease outbreaks. CSA's RADARSAT-2 imagery has been used in Canada to effectively monitor vectors associated with West Nile Virus and Lyme disease, and other similar applications. ${ }^{33}$ Beyond our borders, satellite imagery and tracking is providing insights into the seasonality of avian migration in relation to the spread of influenza and other pathogens including malaria and cholera. These processes have the potential to connect Canada to disease outbreaks in neighbouring countries via international flyways. ${ }^{34}$ Partnerships between CSA, WHO, and the Public Health Agency of Canada are advancing applications of Earth observation for public health decision making and creating a basis for increased tele-epidemiology applications in global health, including for monitoring of public health emergencies under the IHR, such as Ebola and Zika. These partnerships are further essential for informing public health decision-support systems to facilitate timely response and support to States Parties requiring emergency assistance.

Canada is now poised to enter the era of low earth orbit (LEO) satellites, which will contribute to disaster-resilient connectivity, spanning crises from public health emergencies to natural disasters. ${ }^{35}$ These LEO communication solutions by groups such as OneWeb, followed by a larger SpaceX fleet, will allow direct support from satellite to commodity cell phones. Canadian companies such as Telesat Canada and Kepler Communications are also in the milieu. This will provide high-bandwidth voice and data connectivity that is largely impervious to terrestrial disruptions to grid or cable infrastructure. There is funding for LEOs in the 2018 budget for $\$ 100$ million over the following 5 years. ${ }^{36}$

\footnotetext{
${ }^{32}$ Brazeau, S., Kotchi, S.O., Ludwig, A., Turgeon, P., Pelcat, Y., Aube, G., Ogden, N.H. Teleepidemiology and public health in the Canadian context. European Space Agency (Special Publication) 2016.

${ }^{33}$ Brazeau S, Aubé G, Turgeon P, Kotchi S, Michel P. Tele-Epidemiology: Advancing the Application of Earth Observation to Public Health Issues in Canada. 02 May 2014. Available at: https://earthzine.org/2014/05/02/tele-epidemiology-advancing-the-application-of-earthobservation-to-public-health-issues-in-canada/.

${ }^{34}$ Loiseau C, Harrigan RJ, Cornel AJ, Guers SL, Dodge M, Marzec T, et al. (2012) First Evidence and Predictions of Plasmodium Transmission in Alaskan Bird Populations. PLoS ONE 7(9): e44729. https://doi.org/10.1371/journal.pone.0044729.

${ }^{35}$ Z. Qu, G. Zhang, H. Cao, and J. Xie, "LEO satellite constellation for internet of things," IEEE Access, vol. 5, pp. 18 391-18 401, 2017.

${ }^{36}$ Budget for LEOs 2018. http://business.financialpost.com/telecom/ottawas-bet-on-low-earthorbit-satellites-a-positive-step-for-rural-internet-industry.
} 


\subsubsection{Food and Nutrition Security}

Canada has played a longstanding leadership role in the promotion of global food and nutrition security. It is the founding donor of Nutrition International (formerly the Micronutrient Initiative) and is the largest donor to vitamin A programs internationally. Global Affairs works in close partnership with domestic and international agencies such as UNICEF, Helen Keller International, World Health Organization, FHI360, Care Canada, Save the Children, World Vision, HealthBridge, Effect-Hope, and Action Against Hunger, to deliver essential nutrition services. It promotes private investment in agriculture through its active role in the New Alliance for Food Security and Nutrition, a global commitment launched in 2012 by the G-8. Further, Canada is a long-term supporter of the HarvestPlus and efforts to biofortify staple foods with essential micronutrients. Collectively, these efforts contribute to the UN SDG 2: To end hunger, achieve food security and improved nutrition and promote sustainable agriculture.

CSA's remote sensing capability RADARSAT-2 has several powerful features that respond directly to the needs of the agricultural sector and can be leveraged to enhance Canada's impacts in foreign aid. Dual-polarization and quad-polarization modes of RADARSAT-2 allow mapping of crop characteristics over large spatial areas and monitoring of changes in soil and crop conditions over time. Canadian support to foreign aid country partner countries should center around capacity building for the citizen use and uptake of RADARSAT-2 data to mitigate agricultural risks and promote increased production towards improved food security. Capacity building within government, non-profits and the entrepreneurial community could catalyze new innovations in agritech that would have the dual benefit of growing local economies and promoting social impact.

CSA's work in food science has led to development of numerous compact, lightweight and nutritious foods through processes of irradiation, rehydration and thermostabilization. Future deep-space missions to Mars will additionally require biological studies into the growing of plants in outer space. CSA's space tech innovations around food products have the potential to translate to hard-to-reach or austere environments on Earth, such as complex emergencies characterized by armed conflict and food insufficiency. CSA's development of food rations for space travel has generated an understanding of human physiology and diet that may be transferable to Earth in the form of innovative nutritious, low-cost food technologies. There is both a need and an opportunity for Canada to lead the way in the R\&D of novel food rations, such as locally produced ready-to-eat-therapeutic-foods (RUTF), that can save lives in humanitarian aid settings with limited or no reliance on water and energy inputs. Innovations in cellular agriculture, spearheaded by the entrepreneurial community, are creating novel plant-based proteins as well as 'clean meat' in a trend that is poised to revolutionize food-tech globally. Future advances in cellular agriculture, inspired by the need for sustainable space exploration and colonization, could revolutionize food security and democratize access to a healthy, environmentally sustainable, and low-cost diet. 


\subsubsection{Disease Prevention}

Global Affairs Canada is committed to reducing the burden of key diseases causing widespread morbidity and mortality, specifically diarrhea, HIV/AIDS, malaria and tuberculosis (TB), and works in close partnership with its government and development partners to strengthen health systems. Capacity building of front-line community health works and key personnel constitutes a key aspect of Global Affairs work to support improved prevention and treatment of diseases. CSA space technologies such as robotics, satellite communications and biological tools all have relevant applications. Canada's international public health services and are ideally positioned to improve health of vulnerable groups living in remote and isolated low-resource settings.

Successful applications of satellite communication technologies in Canada's rural and remote Northern Indigenous communities for diseases such as HIV/AIDS, TB, and community vaccination programs provide an evidence-base for scaling out these applications to international settings. CSA's communications satellites have enabled eHealth, or information technologies and patient monitoring systems that improve healthcare accessibility and efficiency. They have enhanced telehealth capabilities, such as video conferencing for patient-provider specialist consultations, and improved access to vaccination and emergency services. ${ }^{37}$ Telemedicine applications, such as tele-operated surgical systems, are now possible using both satellite communications and robotic technology developed for Canadarm2. UNOOSA has highlighted the importance of scaling capacity building in telecommunications infrastructure to enable e-learning, e-training and telemedicine and for collection of health in sub-Saharan Africa and Asia Pacific. ${ }^{38}$ Voice-based telemedicine, the emergence of immersive applications, combined with robotic advances, democratize access to care in rural and northern communities, and can extend the reach of health experts to the last mile. CSA has developed several space health technologies that may have applications in global health. ${ }^{39}$ Examples of this include MicroPREP, an automated "lab-on-a-chip technology" that isolates macro-molecules such as DNA, proteins or rare cells as a first step towards personalized or precision diagnostics ${ }^{40}$; and Bio-Analyzer, a portable diagnostic tool to test blood, saliva, and urine, which

\footnotetext{
${ }^{37}$ Khan I, Ndubuka N, Stewart K, McKinney V and Mendez I. The use of technology to improve health care to Saskatchewan's First Nations communities. Can Commun Dis Rep. 2017;43(6):120-4.

${ }^{38}$ Committee on the Peaceful Uses of Outer Space Scientific and Technical Subcommittee Fortyeighth session, Vienna, 7-18 February 2011. Item 5 of the provisional agenda. Implementation of the recommendations of the Third United Nations Conference on the Exploration and Peaceful Uses of Outer Space (UNISPACE III). Available at: https://www.unoosa.org/pdf/limited/c1/AC105_C1_ L305E.pdf.

${ }^{39}$ Rai, A., Robinson, J.A., Tate-Brown, J., Buckley, N., Zell, M., Tasaki, K., Karabadzhak, G., Sorokin, I.V., Pignataro, S. 2016. Expanded benefits for humanity from the International Space Station. Canadian Space Agency. Available at https://ntrs.nasa.gov/archive/nasa/casi.ntrs.nasa.gov/ 20170006172.pdf:

${ }^{40}$ Canadian Space Agency (CSA). MicroPREP: New advances in sample purification. Updated: 2017-11-29. Available at: https://www.asc-csa.gc.ca/eng/sciences/microprep.asp.
} 
may have future applications in disaster relief situations and in medical care in remote settings. ${ }^{41}$

\subsubsection{Disaster Relief}

Global Affairs deploy humans on short notice anywhere in the world in response to situations ranging from natural disasters to complex humanitarian emergencies. The Disaster Assistance Response Team (DART) is a multidisciplinary organization composed of military members and civilians, and works in cooperation with global agencies to stabilize the primary effects of the disaster; prevent the onset of secondary effects of a disaster; support the deployment of humanitarian and sustainable recovery programs. CSA's and Global Affairs' work is particularly aligned in the area of disaster relief through operational partnerships. CSA is a founding member of the International Charter "Space and Major Disasters", ${ }^{2}$ which pools space technologies from countries around the world to facilitate emergency response to natural disasters and support relief efforts. Spillover technologies from these applications include water making and purification advances from the space sector, and hence the potential to provide safe drinking water to reduce the burden of disease during disaster operations. Water making has been a specific impact of the DART program.

By providing accurate and timely information and connecting emergency response teams, satellites play a critical role supporting first responders and search and rescue teams in emergency situations. CSA's RADARSAT-2 imagery has regularly provided support to rescue teams on the ground since the Charter was founded in 2000. Recent examples of this include earthquake response in Nepal in 2015; response to Typhoon Haiyan in the Philippines in 2013; the earthquake in Haiti in 2010; the Gulf of Mexico oil spill in 2010; the tsunami in Indonesia and Thailand in 2004; and over 500 other disasters spanning the globe. To date, CSA has contributed over 1500 RADARSAT-1 and RADARSAT-2 data acquisitions in response to these disasters.

\subsection{Future Directions}

Canada's leadership in space technology is uniquely positioned to make a transformative impact in global health. Innovations in robotics, satellite and radar imagery have catalyzed novel applications in healthcare within Canada and have the potential to inform the country's future directions in foreign aid. Applications of space

\footnotetext{
${ }^{41}$ Canadian Space Agency (CSA). Bio-Analyzer: Instant biomedical results from space to Earth. Updated: 2017-12-07. Available at: https://www.asc-csa.gc.ca/eng/iss/bio-analyzer.asp.

${ }^{42}$ Available at: https://disasterscharter.org/web/guest/home;jsessionid= E835145BC8FC857472ECBD4F03E1C911.jvm1.
} 
technology are particularly well suited to Global Affairs priorities in pandemic preparedness, food and nutrition security, disease prevention and disaster response, and should form an integral part of Canada's foreign aid strategy. As these 'exponential technologies' continue to be tested, validated and scaled worldwide, Canada will need to consider how it can best position the use of digital data generated by these tools to foster accountability and transparency of investments towards the UN SDGs. Partnerships between government, the private and the non-profit sectors will continue to be essential to achieve these goals. With political support and catalytic investments in healthtech, such as Grand Challenges Canada, the SD Tech Fund and the Innovation Superclusters Initiative, Canada aims to commercialize new technology products, processes and services that will improve global health for all.

Acknowledgements The authors wish to thank Audrey Barbier from the Canada Space Agency and Isabelle P Roy from Global Affairs Canada, for their contributions and review of this chapter. 